\title{
AS COMUNIDADES TRADICIONAIS NO VALE DO RIBEIRA: DA “REPRODUÇÃO CAMPONESA" ÀS RE-SIGNIFICAÇÕES DOS PATRIMÔNIOS TERRITORIAIS.
}

\author{
Renata Medeiros Paoliello CLAR/UNESP \\ reluz8@uol.com.br
}

\begin{abstract}
RESUMO: Considerando as mudanças do espaço rural contemporâneo no Vale do Ribeira paulista, e o papel que nestas vêm desempenhando certas modalidades correntes de práticas de reposição dos pequenos patrimônios territoriais relacionadas ao parentesco, o artigo procura re-discutir a proposta de Antonio Candido para o entendimento do mundo caipira tradicional e de suas transformações.
\end{abstract}

Palavras-chave: espaço rural, ruralidades contemporâneas, campesinato, comunidade tradicional, posse da terra, bairro rural.

ABSTRACT: Considering changes in rural contemporary space at Ribeira Valley, state of São Paulo, and the role that certain current practices of replacement of small properties play in it, this paper discusses Antonio Candido's proposal for understanding traditional "caipira" world and its transformations.

Key-words: rural space, contemporary ruralities, peasantry, traditional community, land tenure, rural district.

Este texto constitui uma tentativa de reflexão sobre fenômenos, no mundo rural brasileiro, que vêm respondendo a processos gerais tendentes a deslocar pessoas e relações, acelerados na vida social contemporânea, a partir da realidade específica do Vale do Ribeira, região sudeste de São Paulo. Busca-se, desde ali, delinear algumas linhas de força, possivelmente generalizáveis, que propiciem uma aproximação a outros contextos rurais.

O Vale do Ribeira é, do ponto de vista empírico, privilegiado no que diz respeito a esta discussão, em particular considerando processos que ali vêm ocorrendo nos 
últimos vinte anos. Historicamente posto à parte do desenvolvimento agro-industrial paulista, apresenta um quadro de indefinição fundiária que favorece a posse, ao mesmo tempo induzindo a especulação imobiliária e conflitos, que conduzem à intervenção governamental, visando a regularização e a reforma agrária, nos anos 80 , logo a seguir deslocadas pela legitimação institucional do discurso ambientalista, pela imposição de restrições preservacionistas às formas correntes de cultivo e apropriação da terra, e de "fechamento" da terra devoluta pelas divisas de parques estaduais.

Soma-se a esta situação a ameaça constante de construção de uma barragem no rio Ribeira de Iguape que, ao realizar-se, literalmente faria submergir a expectativa, sempre reposta, do reconhecimento de um direito historicamente construído: aquele vindo do apossamento, que constitui a condição de sitiante, a autonomia de "dono", transmissível a herdeiros, e que fundamenta o movimento das pessoas entre bairros, e em direção a novos bairros. Movimento este fundado em redes de parentesco, cuja etnografia, situada em relação a dinâmicas mais gerais e à história, permite retomar análises clássicas sobre a condição de sitiante, como as de Antonio Candido ( 1979 ) e Maria Isaura Pereira de Queiroz ( 1973 ). Bem como outras, mais recentes, procurando interpretar o contexto dos sitiantes posseiros do Ribeira nos termos de um enfoque que o situa como o lugar da tradição, a meu ver limitado no que toca à compreensão dos processos sociais ali em curso.

Tais processos marcam-se pela recorrência de práticas de movimentação orientadas para a reposição de patrimônios territoriais, seja em locais já estabelecidos, por herança, casamentos ou compra, seja pela abertura de novos espaços, e/ou pela destinação desses patrimônios à reversão em reserva, monetária ou em espécie, voltada a um abandono provisório ou definitivo, da condição de sitiante, procurando-se com ela a aquisição de moradia urbana, o trânsito eventual para o assalariamento, ou a abertura de um pequeno comércio. Alternativas entre outras que, freqüentemente combinadas, sugerem que a mobilidade histórica desse campesinato posseiro é, sempre que possível, retomada estrategicamente para atualizar sua condição.

Assim, na quase ausência atual de alternativas de produção e trabalho, procuram-se redefinir estratégias variadas de atualização de um direito à terra, incluindo, quando é o caso, a reivindicação do reconhecimento de um território como 
remanescente de quilombo. Capital material e simbólico, a terra é patrimônio herdável, mas também divisível e negociável, local de moradia complementado por assalariamento eventual, reserva de valor e, no limite, instrumento de passagem para a vida urbana. Enfim, a terra-patrimônio pode ser re-significada sob todas essas modalidades. O reconhecimento do direito sobre ela constituído torna-se, então, demanda de cidadania e de inserção, ainda que precária, nos campos jurídico e político.

A partir desse contexto, no qual desenvolvi pesquisa nos anos 80 e 90 ( Paoliello: 1992; 1998; 1999 ), tendo por objeto os conflitos em torno da posse da terra e as estratégias de reposição dos patrimônios possessórios, particularmente as que resignificam direitos de herança, busco relativizar recortes analíticos mais estáticos, orientados para uma oposição entre permanência e mudança, voltando-me para uma abordagem mais processual, mais sensível ao que o "dado" empírico pode repropor aos nossos modelos interpretativos, em particular no que diz respeito a situações lidas como "tradicionais", e vistas como pressionadas por sucessivas dinâmicas "vindas de fora". Em face dos fenômenos e processos observáveis no Vale, o que este texto pretende é apresentar sumariamente algumas sugestões para rediscutir o significado, desde o ponto de vista dos agentes envolvidos em tais processos, de conceitos pelos quais habitualmente vimos pensando o mundo rural: terra, família, parentesco, bairro rural, etc.

O foco sobre as reconstruções de uma ruralidade, partindo do estudo de Candido sobre o mundo caipira, leva em conta que este estudo da vida caipira tradicional e das mudanças que atravessa no momento em que o autor dela se acerca, pode ser reconsiderado diante das tensões e conflitos em torno do acesso à terra, particularmente em São Paulo, após meio século de desdobramento das mudanças mapeadas por Candido, A estas se agregam novos condicionantes e incidências, tais como a consolidação das agro-indústrias, a intensificação das migrações, a dissolução das relações correntes no mundo rural paulista e, mais recentemente, a desocupação dos trabalhadores safristas com a mecanização agrícola crescente, a irresolução da questão agrária, mantendo-se o não reconhecimento de formas social e juridicamente legítimas de relação com a terra, e o advento da questão ambiental, para citar alguns.

Nesse sentido, como universo concreto de referência e contraponto, o Ribeira se define por processos específicos, tanto no que se refere a sua história como a suas 
circunstâncias mais recentes. Cabe destacar aqui que ele é visto como região em descompasso crônico com o desenvolvimento do estado de São Paulo, em virtude de obstáculos naturais como terra e clima ( Petrone: 1966; Queiroz: 1967 ), da indefinição de seu quadro fundiário, da "caipirização" que se instaura a partir do século XIX, entre outros fatores, impedindo que se integre ao desenvolvimento urbano-industrial ( Muller: $1980)$.

É esta avaliação que vai inspirar, em boa parte, a política de regularização fundiária do governo do estado, que atinge o Vale em meados dos anos 80, momento de crise e desemprego na indústria paulista, que induz um fluxo migratório para as áreas de posse da região, significativas em número e extensão, e de implemento do Plano Nacional de Reforma Agrária da "Nova República". Mais recentemente, a problemática que o tensiona traz como componentes, conflitantes entre si, e sobrepostos à questão fundiária, os projetos de construção de barragens no Ribeira, visando o “desenvolvimento regional”, em particular a de Tijuco Alto $\left({ }^{1}\right)$, a regularização jurídica dos territórios remanescentes de quilombos, nos termos do artigo 68 da Constituição, e a questão ambiental, que se traduz na delimitação de áreas de preservação, entre elas grandes parques estaduais, com o objetivo de resguardar a "última reserva de Mata Atlântica" do estado $\left({ }^{2}\right)$.

O que este texto pretende fazer, então, é um breve balanço da contribuição de Antonio Candido, destacando alguns pontos nodais da proposta de Os Parceiros, discutindo-a a partir do contexto específico do Ribeira, também de cultura caipira, mas com especificidades históricas e sociais que lançam alguns desafios à interpretação de Candido, e, ao mesmo tempo, mostram empiricamente a atualidade de seu pensamento. Por fim, procura-se traçar um também breve delineamento da problemática interpretativa suscitada a partir desse contexto.

1 . O projeto é da Companhia Brasileira de Alumínio, empresa do grupo Votorantim, e se encontra, no momento, paralisado, entre outras razões, pela atuação do Movimento dos Atingidos por Barragens. Outras barragens projetadas desde os anos 60, foram Itaoca, Funil e Batatal, da Companhia Energética de São Paulo, cuja implementação não teve continuidade.

2 . É ilustrativa desses processos a situação atual do município de Iporanga, que tem sua área quase que totalmente abarcada pelo Parque Estadual do Alto Ribeira - PETAR -, cuja população de nove mil habitantes decresceu, nos últimos anos, para quatro mil e quinhentos habitantes, em virtude das inviabilidades ocupacionais e produtivas causadas pela presença do Parque, segundo considerações dos próprios moradores, expressas durante minha última visita à cidade, em julho de 2003. Uma vez confirmado esse deslocamento, seria importante verificar para onde se dirigiu esse contingente, se para os municípios vizinhos, para outros pontos da região ou para fora dela, ou em que porcentagem para cada um desses espaços, e quais as motivações para tais escolhas. 
O Vale do Ribeira apresenta marcadamente a recorrência de bairros e sítios constituídos por posse, em geral não legalizada. Esta é a base em que se agudizam os conflitos dos anos 80. Sumariamente, através da multiplicidade de origens e de arranjos que as situações possessórias comportam, um traço geral aparece: o direito ligado à posse é concebido individualizadamente, assim como a herança dos patrimônios assim constituídos nunca permanece indivisa. Nas falas, esse valor emerge particularmente nos conflitos e nas intervenções institucionais.

É essa presença forte da posse nas práticas e nas representações, que ultrapassa o plano de um discurso estratégico para confrontar a iminência da perda da terra, que conduz a uma reconstrução histórica para compor uma interpretação do sentido do direito à terra, ligado, por outro lado, a uma dinâmica de mobilidade que funda e refunda patrimônios e bairros, sustentada pelos vínculos de parentesco, como se verá adiante.

Essa reconstrução, aliada à observação dos processos presentes, leva a supor que, face a essa dinâmica de mobilidade, este é um contexto aberto à mudança. No presente, não se conforma como um todo coeso, mostrando uma multiplicidade de arranjos permeados por valores e relações em fluxo ( Vincent: 1987 ). Reconstroem-se, no entanto, laços sociais, em particular por meio de estratégias de re-fundação das posses, e de trânsitos de pessoas entre bairros, sustentados por direitos oriundos de herança, casamentos ou compra de terras. Os direitos de herdeiro aí são fundamentais. Alguém é herdeiro por linha paterna ou materna, e tem seus direitos reconhecidos, permaneça ou não em seu bairro de origem. Caso a herança em sítio paterno, seja inviabilizada por insuficiência de terra para as partilhas, ou se reclama direitos da mãe, ou se compra, ou "posseia" em terra "sem dono", "do governo", no "mato bruto" ou "sertão", carregando parentes para reforçar a posse, e estabelecer a vizinhança, fundando novo bairro.

Sempre que há insuficiência de terra, a mesma prática se repõe, para abrir áreas de cultivo, principalmente comercial, fora do local de moradia, ou se procura arrendar terra. A terra, assim, é, ela própria, móvel, sendo o parentesco o principal instrumento de sua reposição. Concebida como patrimônio, embora não estável, ela é de trabalho, mas também de negócio. Associada a um "cabeça de casa”, ou a alguém que se individualiza como herdeiro, ela costuma abrigar uma família conjugal, porque nunca 
permanece indivisa por muito tempo, entendendo-se que filhos emancipados, e casados, são pares de seu pai, portanto não se submetem a sua autoridade.

A variedade de arrranjos para acostar as dificuldades produtivas e o vínculo não legalizado com a terra, percebido como precário, responde a projetos e expectativas relativos ao futuro dos filhos, face às incertezas quanto ao patrimônio. Assim, uma vez limitada economicamente a ajuda mútua, surgem estratégias de assalariamento complementar, de distintos membros da família, entre outras, ou de compra de trabalho, chegando-se ao limite de substituir ou vender o sítio. Mas não obrigam, da parte dos filhos, ao ingresso de recursos. As saídas destes, por sua vez, são freqüentes, e não significam, necessariamente, a perda de direitos de herdeiro.

Em linhas gerais, um tal quadro permite supor que este é um campesinato que não preenche os modelos correntes, ou que nos sugere alargar tais modelos. Orientado por um habitus "permeável à mudança" porque compartilha certos valores específicos com o mundo social em que se insere, cabe considerar suas estratégias em face de contingências objetivas como informadas por relações históricas, culturais, econômicas e políticas.

Para tal, refletir sobre a atualidade da contribuição de Os Parceiros é importante. É possível concordar com o entendimento de alguns autores que ressaltam hoje a relevância de Antonio Candido nas ciências sociais brasileiras, apontando a radicalidade de seu pensamento ( Santos: 2002 ). Radicalidade que se exprime no posicionamento político de Candido em favor da reforma agrária, defendendo sua urgência, e na sua retomada inovadora, sociologizante, de uma tradição intelectual ensaística, que vem de Caio Prado Jr., Sérgio Buarque de Holanda e Gilberto Freyre, cujo foco é a teoria dos dois Brasis, o agrário e o urbano, o entendimento da sociedade brasileira como recortada pelo eixo tradição/modernidade, para pensar seu jogo entre permanência e transformação. O que a sócio-antropologia de Antonio Candido proporá é seguir o curso da formação histórico-social do país, para analisar as condições históricas da mudança, a partir de um contexto rural específico, mas significativo, em que esta se faz expressiva ( Garcia Jr. \& Grynzpan ) ${ }^{3}$.

\footnotetext{
3 . GARCIA Jr. \& Grynzpan (2002 ), em sua discussão sobre os estudos rurais brasileiros, a respeito de uma visão crítica do dualismo das análises que operam com a antinomia tradição/modernidade, que marca a teoria dos dois Brasis, entendem que Antonio Candido, como Maria Isaura Pereira de Queiroz, compõem uma segunda geração de cientistas sociais que se desloca do foco na vida agrária brasileira como matriz da nacionalidade para pensar a modernização por seu vínculo entre a
} 
Este olhar histórico, processual ( Jackson: 2002; Passiani: 2002 ), é o que remete a proposta teórico-metodológica dos Parceiros para além dos estudos de comunidade, e de seu recorte tipológico mais estático. Nesse sentido, ele inova, ao substituir o conceito central de comunidade, enquanto unidade de análise, equivalente a um todo auto-contido cultural e territorialmente, tal como formulado por Robert Redfield, e incorporado a partir de estudos europeus sobre campesinato, pelo de bairro rural, mais fluido para caracterizar a realidade rural brasileira, especialmente a caipira, de mobilidade territorial e de vínculo mais frouxo com a terra.

Tal inovação conceitual é o núcleo da contribuição de Candido, que é a de recusar um apriorismo de método ( Santos: 2002 ), para construir o recorte teóricometodológico de acordo com o fenômeno empírico focalizado, isto é, com suas linhas de força históricas e sociais. Esse fenômeno é o da pequena propriedade e da parceria, impactadas pelas transformações da vida rural, para preparar um estudo posterior da reforma agrária como meio de inclusão, com papel decisivo na modernização do país. É precisamente na reconstrução sistemática de um modo de vida situado, mas que se explica historicamente, por referência a um processo maior, e de sua re-inserção problemática num contexto macroscópico em mudança, que Candido abre uma perspectiva passível de ser reconsiderada hoje, diante de dificuldades conceituais e metodológicas a que conduzem os processos sociais rurais contemporâneos.

Em particular, no que toca à diversidade de respostas específicas e concretas das populações rurais a dinâmicas que vêm conduzindo um processo de deslocamento, expropriação e pauperização crescentes, ao lado de abrir possibilidades novas à ruralidade, à re-incorporação, em novos termos, de práticas e valores urbanos, aos trânsitos para a vida urbana, às múltiplas interações entre o rural e o urbano, às reconstruções dos laços sociais. Respostas estas que parecem envolver, como o caso da posse no Ribeira manifesta, re-significações estratégicas de práticas e valores históricos, freqüentemente relacionados ao parentesco e à terra, e que sugerem linhas gerais

questão agrária e a construção do Estado. Nesse sentido, distanciam-se da ênfase na mestiçagem como chave para entender as especificidades e as razões do "atraso" relativo, privilegiando a interpretação voltada aos seus fundamentos históricos e sociais. Garcia e Grynspan, ao delinearem a perspectiva da terceira geração, dos anos 70, marcada pela institucionalização dos programas de pós-graduação e pesquisa, e, portanto, voltada a uma ênfase à pesquisa empírica rigorosa, e à correspondente crítica aos estudos de comunidade, produzidos pela geração anterior, distinguem Candido e Queiroz como antecessores dessa nova geração no que toca ao rigor da pesquisa, à sensibilidade ao empírico, e à tomada de distância do ensaísmo da primeira geração. 
atualizadas diferenciadamente no mundo rural brasileiro. Em suma, trata-se de incorporar à análise sociológica e antropológica a reconstrução da história das populações rurais, cuja relevância foi reiterada recentemente ( Wanderley: 1996; Palácios: 1993 ).

Em outros termos, pensando-se no trabalho de reconstrução histórica que Candido exemplifica tão bem, complementar a sua atenção aguda ao empírico, cabe testar constantemente os grandes conceitos com os quais opera a reflexão antropológica sobre o rural, a partir desse empírico, evitando a tendência a fazê-los recobrir categorias históricas, como sitiantes, posseiros, lavradores, parceiros, arrendatários, volantes, semterra, assentados, etc., como bem notam Garcia e Grynzpan. Em suma, abandonar a visão do polo rural como locus do tradicional que, embora se tenda hoje a valorar simétrica e inversamente por oposição a uma modernidade negativamente avaliada, repõe, sem percebê-lo e problematizá-lo, o dualismo e os estigmas que o acompanham.

Para os objetivos desse texto, concentro-me na articulação feita por Candido entre reconstrução histórica e interpretação sociológica para a análise do mundo caipira, a partir das transformações concretas nas relações de parceria, cujo núcleo é a releitura do enfoque de Redfield sobre o campesinato: para entender as sociedades que define como rústicas, Candido nelas identifica características culturais camponesas, vendo-as como 'sociedades parciais dotadas de culturas parciais', ou seja, como compartilhando com o mundo urbano um mesmo sistema de valores, e relacionando-se com ele, jurídica, política e econômicamente, constituindo, assim, o contínuo rural-urbano, tal como Redfield o propôs para a abordagem das relações campo-cidade ${ }^{4}$. Mas, como já comentado acima, Candido inovará, traduzindo o conceito de comunidade, pensado por Redfield como todo circunscrito no espaço e no plano das relações e concepções, unidade analítica do mundo camponês "tradicional", pelo de bairro, expressão territorializada, mas não fixa, de um agrupamento que se constitui por um esquema mínimo de relações sociais.

\footnotetext{
4 . Os conceitos de part-society e part-culture, primeiramente formulados por Kroeber, vêm substituir, no pensamento de Redfield, incorporando críticas, como nota Antonio Candido, aquele anterior, de sociedade ou cultura de folk, que aproximava realidades camponesas a sociedades tribais, sendo, portanto inadequado e insuficiente para entender as relações rural/urbano. São eles, agregados à idéia de comunidade camponesa, inspirada em estudos europeus de campesinato, que permitem a Redfield formular o modelo do contínuo rural/urbano para focalizar contrastivamente um polo e outro, e analisar as transformações que o segundo induz no primeiro. Este é o modelo teórico-metodológico que influenciará uma vertente da sociologia rural, representada na França por Henri Mendras, e aqui por Maria Isaura Pereira de Queiroz.
} 
A importância do foco histórico aparece aí, na medida em que Candido elabora o conceito de bairro a partir de uma reconstrução do contexto colonial em que ele vai interpretar a constituição de uma sociedade, nesses primórdios do Brasil, desde uma dinâmica adaptativa em que, diante de novas condições, teriam sido perdidos traços organizativos comunitários, advindos do campo português, e adquiridas, em substituição, formas indígenas de incorporar socialmente o espaço para produzir os meios de vida. Esta teria sido, segundo Antonio Candido, a gênese do modo de vida caipira, e de sua cultura organizada em torno de mínimos, vitais e sociais, e marcada pela mobilidade territorial e de cultivo, supondo formas de relação que a propiciem.

Essa interpretação histórica carrega a perspectiva de Candido, sua ênfase à função adaptativa da cultura, ou seja, à cultura como mediadora da satisfação das necessidades básicas. A organização sócio-cultural, nesse sentido, é um mecanismo de ajuste ao meio para promover o equilíbrio entre necessidades e recursos. Esse equilíbrio é variável e, nas sociedades mais diferenciadas, exprime-se em sub-equações, como aquela entre camponeses e citadinos. O que Candido aí explicita é uma postura relativista na abordagem das distintas formas, no tempo e no espaço, de equacionar este equilíbrio. Por exemplo, a incorporação de um mundo rural a uma cultura urbana conduz à reavaliação do modo de vida em função dos novos padrões definidos por esta cultura. Desse modo, é possível falar em mínimos em termos comparativos.

No entanto, considerando os mínimos abaixo dos quais os equilíbrios podem ser rompidos, Candido entende que há traços disfuncionais nas culturas que dificultam a integração de certos grupos em situação de mudança. Algumas culturas operam por um equilíbrio mínimo entre necessidades e recursos, entre mínimos vitais e sociais, por técnicas e formas de organização social rudimentares. Nestas, a preocupação alimentar domina e compromete o desenvolvimento de outros aspectos da cultura, impedindo assim o desenvolvimento de outros recursos adaptativos e integrativos. O modo de vida caipira manifesta essa condição, pelas razões históricas que Candido reconstrói.

Esse ponto de vista, em síntese, faz uma releitura do modelo comunitário, visando o Brasil rural, para ressaltar a importância do papel integrador da comunidade de vizinhança, traduzida no conceito de bairro, relativamente ao da família, no que toca a uma sociabilidade mínima requerida para assegurar a subsistência. Em suma, o risco constante, para uma sociedade organizada em torno de mínimos, é o de escapar àquela 
sociabilidade mínima que permite a cooperação numa divisão do trabalho mais diferenciada, é o do isolamento, caracterizado pelo refluxo para o interior da família, cujo fator dinâmico é a mobilidade exigida no processo de ocupação territorial, que condiciona a morfologia e o funcionamento sociais. E que, segundo Candido, marca para sempre o caráter do caipira, e conforma a fluidez de seu vínculo com a terra, ao contrário da fixação própria das comunidades camponesas européias.

Para repensar a atualidade do ponto de vista de Antonio Candido a respeito dessa sociabilidade comunitária mínima para assegurar a cooperação e a subsistência, realizada na forma do bairro, cabe lembrar aqui que as relações sociais que tecem a sociabilidade constitutiva dos bairros rurais, e sua dinâmica de mobilidade territorial, são fundamentalmente as de parentesco intra e extra família conjugal, que é a forma familiar caipira predominante, como mostra Maria Isaura Pereira de Queiroz. A mesma autora descreve a dinâmica central da vida rural caipira, que se move nos pólos bairro rural, que é comunidade de parentes, e avanço de famílias conjugais sobre novas áreas, refundando novos bairros, abrindo a possibilidade de que a estes se agreguem parentes ( Queiroz: 1973 ). Esta é a dinâmica da mobilidade permanente, que marca o mundo caipira, e caracteriza aquela nova forma de organização social de que fala Candido. As áreas de posse do Vale do Ribeira, tanto em seu movimento intra-regional, como naquele que decorre de migrações de áreas caipiras avizinhadas, manifestam claramente, na sua história, e até o presente, essa dinâmica ( Paoliello: 1999 ).

Trata-se, assim, de pensar se não é o parentesco, que se define no âmbito restrito da família nuclear conjugal, mas que também e principalmente é rede que comporta descendência e aliança, e ultrapassa a unidade familiar, que se projeta, e, no caso caipira, por meio dessa forma histórica e concreta da mobilidade, no espaço como no tempo, visando assegurar, antes que a regularidade e a reprodução dos meios de vida, as atualizações e reconstruções dos laços sociais e dos direitos sobre a terra. Portanto, não nos referimos só ao âmbito da unidade familiar de produção e consumo, e ao seu ciclo curto, onde se correria mais o risco de uma sociabilidade disfuncional à obtenção dos mínimos, segundo Candido, mas a essa forma de organização social móvel, mais plástica, que engloba família conjugal e rede de parentes, que vem respondendo às condições históricas que se lhe apresentam, e que se constitui numa rede de bairros rurais em constante movimento. De pessoas e de famílias que os fundam e refundam ao 
se moverem para áreas novas, ou que transitam entre eles, por herança, casamento e migrações, suportadas pela rede de parentesco e tudo que esta significa em termos de sociabilidade e recursos. Seria ele o fator relacional e organizativo central da vida rústica, que está, como prática e como valor, por trás das relações de vizinhança, configuradas no âmbito de cada bairro. E que sustenta a mobilidade, tão significativa em face das condições históricas, sociais e jurídicas, e não parece estar restrito ao mundo caipira, manifestando-se em outros contextos rurais, compondo suas relações com o mundo social englobante.

A questão da dinâmica característica da mobilidade e do isolamento pode, então, ser vista sob nova luz, reforçada pela perspectiva de Maria Isaura Pereira de Queiroz, que mostra ser o isolamento do caipira em boa parte ilusório. Candido já o fizera, desmontando o olhar discriminador que via no homem rural paulista o exemplo do atraso e da decadência, afundado no sertão em estado quase natural, afastado de qualquer sociabilidade que merecesse este nome. Mas, para Candido, tendo em vista suas condições adaptativas reduzidas a mínimos, o fantasma do isolamento, enquanto fator regressivo, e explicativo da insuficiência alimentar que sempre ronda o universo simbólico do caipira, ameaça constantemente. E o isolamento é conseqüência da mobilidade, da pouca fixação à terra, que tende a desfazer aqueles laços comunitários vicinais, realizados no bairro, por oposição à família, vista como individualizante, portanto fator de desagregação da relação comunitária básica, e, assim, de anomia.

Maria Isaura descreve com riqueza aquela dinâmica bairros/avanço sobre terras virgens/fundação de novos bairros, sustentada pelo parentesco, tal como indicada acima. Mostra também como esta constituição social móvel se relaciona em complementaridade às cidades, até um certo momento do desenvolvimento urbano, quando estas relações se tornam de subordinação. No Vale do Ribeira, é visível contemporaneamente, embora nela se introduzam novos fatores, essa dinâmica de mobilidade regionalmente circunscrita ( Bourdieu: 1989 ) ${ }^{5}$, fundada em relações de parentesco, informando estratégias sociais, econômicas e espaciais para fazer face

\footnotetext{
5 . A idéia de região aqui assumida toma por referência a discussão de Pierre BOURDIEU ( 1989 ), segundo o qual a região é pensada como construção social, produto de relações sociais, não como realidade física. É dessa realidade social que retira sua objetividade. Para o caso das estratégias possessórias historicamente marcantes no Vale do Ribeira, e que configuram o território regional do ponto de vista externo inclusive, são as redes de relações fundadas no parentesco, ultrapassando mesmo seus limites geográficos, que constróem em boa parte o espaço físico em questão.
} 
àquelas mudanças apontadas alguns parágrafos atrás: restrições preservacionistas, possibilidade das barragens, irresolução da questão fundiária, falta de alternativas produtivas e ocupacionais.

Assim, ela pode ser definida como uma dinâmica que se atualiza, como forma ativa de construir trajetórias possíveis, e assegurar um espaço social de existência. Provavelmente porque as relações sociais em geral, especialmente no que toca à terra, em certo sentido - o de reconhecimento de direitos e de possibilidades de acesso e permanência -, pouco mudaram, ao lado da pouca oferta de alternativas de produção e de trabalho, e assim sendo, da frustração de expectativas de melhoria.

Esse quadro sugere que as atualizações da mobilidade não constituem necessariamente um fator regressivo, de anomia e miséria. Se as situações de isolamento na verdade ocorrem, elas não resultam de uma espécie de pulsão cultural interna do caráter do caipira, mas de processos mais gerais da sociedade de cujas dinâmicas participa. Até porque, como Candido nos mostra, historicamente a mobilidade se relaciona ao movimento geral de abertura do território, e de terras à grande propriedade.

Não por outra razão, aquilo que aparece de imediato como abertura da terra por derrubada, queimada e cultivo itinerante, é o ato do apossamento, ou seja, da constituição de um direito sobre a terra assim incorporada às relações humanas, para o “desbravador" e para seus descendentes e demais parentes, em escala decrescente de proximidade do vínculo. E o que não se vê, se o foco fica restrito ao processo de abertura e cultivo, é a incorporação simbólica, e, portanto, social, da terra, já antes da abertura: o "sertão", o "comum" disponível ao avanço de novas famílias, a "reserva", de caça e produtos extrativos, de lenha e madeira, e de outros recursos, principalmente a terra. Ao mesmo tempo difuso, porém atingível, sempre redutível, aos olhos e aos atos, como às relações, de parentesco e vizinhança, mas antes relações de direitos, constituídos nesta prática, orientados por valores compartilhados com a sociedade englobante, e esperando seu reconhecimento. Assim, a sugestão é a de que esta "latência regressiva" suposta por Candido possa ser vista como a estratégia sóciohistórica, até aqui disponível a populações rurais, em particular a "caipira", para atualizar-se, para reconstruir recorrentemente suas condições de vida social. 
No caso do Ribeira, os riscos aos quais tal estratégia permite responder repõemse, desde os anos 80 , no que se refere aos conflitos fundiários e ao impacto de uma reforma agrária incapaz de considerar as formas correntes de constituição de direitos sobre a terra, e de um preservacionismo incapaz de levar em conta a presença humana histórica compondo um habitat; tudo isto inviabilizando a manutenção das formas correntes de atividade econômica, e/ou a inovação desta atividade. Um dos poucos recursos para confrontar esta situação é aquele propiciado pelo artigo 68, das disposições transitórias da Constituição federal, que assegura o reconhecimento legal das áreas "remanescentes de quilombos", dispositivo de lei ao qual procuram enquadrar-se os "bairros de pretos" do Vale, e que sofrem, concentradamente, todas estas ameaças à sua continuidade.

Em suma, uma escalada de riscos que se acumulam há décadas, sobrepondo-se uns aos outros, e ameaçando precisamente aquilo que - e as falas dos sitiantes e moradores do Vale o revelam - vem sempre sendo a componente crucial de sua organização social, a mobilidade. Das "grilagens" à regularização e à reforma, seguido do ecologismo institucional que, sobre uma série de dificuldades produzidas a partir do fechamento das possibilidades de extensão dos lotes, e de uso complementar de áreas exteriores às parcelas admitidas pela legislação do INCRA, impõe rigorosíssimas restrições de uso e ocupação. Em particular quanto às derrubadas, chaves para a expansão das áreas de posse, além do cultivo, para não falar nas práticas de caça e pesca -, compondo um conjunto que tende a praticamente inviabilizar o reconhecimento social e legal dos bairros e dos sítios, e conduzindo à improdutividade.

De outro lado, as tensões envolvidas na produção da subsistência claramente não atingem as proporções de outras regiões, dada a relativa fartura regularmente obtida do cultivo das roças, desde que seja possível operar o padrão de "rodeio" ( cultivo itinerante, via rodízio de roças e/ou abertura de novas áreas ), ou repor, mediante insumos e canais de escoamento, as condições de plantio e de comercialização - e aí os reclamos contra as limitações impostas pelo INCRA, bem como as ecológicas, e também contra a falta de acesso a créditos de custeio, por insuficiência titular e pelo risco de perda acarretada pela hipoteca da terra ao banco. Porque, nesta região especialmente, não se pode desconsiderar que as lavouras voltadas ao mercado são pensadas e praticadas como um componente fundamental daquela expectativa de 
fartura. As tensões nas relações com o Estado e com a sociedade englobante alimentamse das frustrações relativas a tais projetos de melhoria de vida.

Isto sem contar a orientação histórica da produção exportadora arrozeira do Vale, não restrita às fazendas, principalmente no suposto período da "caipirização" ( em que muitos fazendeiros residentes em Santos e São Paulo obtinham os retornos do arroz cultivado por seus arrendatários caipiras ), ainda forte como valor no imaginário dos mais velhos, e que provisionava tanto as cidades da região como São Paulo e Santos, tendo até certo momento ultrapassado as fronteiras tanto paulistas como nacionais, operando naquilo que Pereira de Queiroz entende como uma relação de complementaridade com o mundo urbano. De modo que "fartura" significa plantar para "sobejar" e vender, além de suprir a alimentação. Este plantio para sobrar, e vender, torna-se, sempre que possível, introdução de lavouras comerciais, como a banana, o chá e o maracujá.

Todas as restrições a esta "fartura" almejada e, sempre que possível, produzida, nas falas dessas pessoas, reduzem-se, então, a uma lógica, a ser confrontada: se se fecham legal e institucionalmente as possibilidades da prática de apropriação e cultivo itinerantes, sem compensação titular e creditícia de produção e comercialização de alimentos, vistos como destinados a abastecer o mundo urbano e a sociedade em geral, o que se produz localmente é a miséria, já que, também, não se abrem alternativas de trabalho, que permitam sair, total ou parcialmente, da condição de pequenos produtores agrícolas. Resta projetar o futuro dos filhos, e esperar que o acesso à educação escolar lhes propicie esta passagem para o assalariamento, rural ou urbano, total ou complementar, principalmente favorecido se se conseguir manter a terra, e transmiti-la aos descendentes, como reserva mínima e/ou local de moradia. Expectativas e projetos, em suma, voltados à reafirmação de um espaço social de existência, e de uma presença na arena política, ainda que tudo isto se marque pela precariedade material e institucional, ou até por isso.

Em contraponto, desde a perspectiva de Candido sobre a situação de mudança que incide sobre a parceria, na Bofete dos anos 40, trata-se de pensar a integração do rural ao urbano como processo que supõe uma reformulação simbólica, pensada como mais fácil para contextos que se organizam além dos mínimos, redefinindo as formas de organização social, mediadoras centrais do equilíbrio entre necessidades e recursos. 
Processo este que significa a capacidade de assegurar, em escala crescente a regularidade dos processos sociais. Essa regularidade, contudo, não se faz de modo homogêneo, como o demonstram as tensões relacionadas à subsistência entre populações de progresso técnico limitado ou entre classes subalternas. É o caso da “civilização caipira", que se sustenta no deslocamento.

Entender "de dentro" essas populações, bem como esse processo recorrente de reintegração, significa descrevê-las e analisá-las em sua dinâmica oscilante, que se manifesta no espaço, no movimento pendular entre casa isolada e grupo de vizinhança, no interior do qual os sitiantes se constituem como "proprietários fixados na herança". Ou seja, na condição privilegiada de ascensão, na autonomia de "dono", situação almejada e primordialmente valorada no universo caipira, entre outros.

É, segundo Candido, na situação da "casa isolada" que o risco de decaimento abaixo do mínimo, social e vital, agudiza tais tensões, e se conforma muitas vezes como "decadência". Na imagem dessa curva, marcada por um ponto crítico de inflexão, o da organização social na forma de laços que extrapolam a família concebida como unidade natural, relativamente ao qual um mundo social decai ou progride, Candido busca enfatizar a "função estabilizadora" da estrutura de vizinhança e da posse da terra, critérios gerais de regularização e de evolução das sociedades humanas.

A função estabilizadora das estruturas grupais, então, conforma o foco sociológico de Candido, na medida em que é a divisão do trabalho social promovida nestas estruturas o fator do desenvolvimento civilizatório, ou seja, da capacidade decisiva, em maior ou menor grau, que qualquer arranjo societário, em algum nível, deve apresentar para redefinir-se, diante da mudança histórica, do contato com outras formas sociais, ou da própria mudança de suas relações com o nível societário maior no qual se encontra contido. Quanto menos diferenciado um grupo, ou uma sociedade, no que toca à atribuição de funções e, portanto, à colaboração, na divisão do trabalho, quanto mais uma sociedade é capaz de se organizar e reproduzir a partir de unidades auto-suficientes, mais ela sofre a desvantagem, ao lado de vantagens, de ser pouco adaptativa, pouco ágil para inventar recursos diante de imprevistos e mudanças. Ou mesmo, de não produzir sua própria mudança.

Assim, num processo de incorporação (ou reincorporação ) à cultura urbana em transformação, e que, portanto, tende a transformar os mundo sociais que engloba, 
supondo, como já vimos acima, que esses mundos irão redefinir seus padrões de avaliação das condições de vida em face dos novos, que a cidade apresenta, o mundo caipira redefine seus mínimos. E o faz no limite em que a sociedade englobante não lhe oferece as compensações integrativas esperadas, de acordo com os novos parâmetros, às perdas que lhe acarreta.

Entre as atitudes possíveis frente às pressões da mudança, é o refluxo ao grupo familiar ou vicinal que conforma uma regressão adaptativa, cujas resultantes são a instabilidade e a crise, na medida em que se manifesta na retomada da mobilidade histórica deste campesinato. Esta forma de adaptação não mais significa, porém, busca de novas terras e prática da agricultura itinerante, mas fuga à sujeição econômica total que a transformação geral causa a um modo de vida beirando sempre a disfuncionalidade dos mínimos, e prescindindo da estabilidade e da posse da terra.

Tal adaptação não é a melhor resposta aos obstáculos à necessária estabilização das relações, nesta passagem à economia aberta, dependente dos centros urbanos. Para Candido, a chave da resposta integrativa ao processo de modernização é, portanto, a estabilidade do pequeno agricultor caipira na terra, e, para isto, a defesa da reforma agrária é central. É a possibilidade de integrar dessa forma, produtiva e culturalmente, essas populações a um processo civilizatório novo, que significa "urbanizar", não implicando necessariamente a migração para as cidades, mas a inclusão às dinâmicas econômicas, culturais e políticas que constituem o desenvolvimento urbano-industrial moderno.

O mundo urbano, nesse sentido, é visto como aquele que concentra gente e recursos, não só materiais, para um desenvolvimento civilizatório. No entanto, esse processo carrega-se de ambigüidade na medida em que está marcado pela oposição entre o campo, lugar tendente ao isolamento, e a cidade, onde tudo se condensa para aquele desenvolvimento. "Urbanizar", portanto, é dirigir-se a uma possível superação desta cisão, é ultrapassar a concentração da propriedade, fator que contrapõe os interesses do homem da cidade aos do homem do campo, levando-os a pensar seus respectivos mundos sociais como fronteiras naturais insuperáveis.

Dos anos 50, quando Candido formula sua análise, para cá, o "processo de modernização", não só no Brasil como em escala global, apresentou desdobramentos inesperados e mudanças agudas, nos planos político, social, cultural e tecnológico. Em 
primeiro lugar, para o caso brasileiro, no que se refere à reforma agrária, são dois os momentos em que esta é, em boa medida, abortada: nos anos 60 , e nos 80 . Tenha-se em conta, nesse sentido, que a legislação agrária, formalmente visando a reforma, desde o Estatuto da Terra até o Plano Nacional de Reforma Agrária, de 1985, e os dispositivos constitucionais que a contemplam, em 1988, atendem a expropriados estritamente, e não a sitiantes posseiros e às demais formas correntes de apropriação, freqüentemente referidas a princípios jurídico-legais históricos incorporados às práticas sociais, que as leis civis e agrárias vigentes não prevêem explicitamente. Em suma, o corpus legal contempla insuficientemente situações de posse, a serem regularizadas, uma vez que permanece sob jurisdição dos estados, aos quais está atribuída, desde a primeira Constituição republicana, a propriedade das terras devolutas, onde em geral se localizam as áreas de sítios e os bairros rurais. Por outro lado, a questão da concentração fundiária não se soluciona, passando-se do "clássico" latifúndio agro-exportador para a agro-indústria, sem que se problematize a distribuição mais equilibrada dos patrimônios territoriais.

Em segundo lugar, o que vem a acontecer, nesse período, é a crise do modelo produtivista urbano-industrial. Em suma, a crise dessa forma de modernização, de dimensões globais, e desde a qual uma outra dinâmica modernizadora emerge, caracterizando-se pelas transformações tecnológicas que suportam um processo de mundialização econômica e cultural ( Augé: 1994; Giddens: 1991 ), no qual o Brasil se insere de modo problemático, envolvendo a exclusão, ou a "inclusão perversa", de seus contingentes populacionais subalternos, crescentemente empobrecidos.

É neste processo, aqui muito sumariamente traçado, que se deve recolocar a questão da ruralidade no Brasil contemporâneo. Até porque é, entre outras razões, desde uma questão agrária não resolvida, a que se sobrepõe a questão ecológica, um dos eixos fundamentais das mudanças contemporâneas de uma dinâmica econômica para a qual se torna crucial conservar ( e controlar ) recursos que agora se percebe serem esgotáveis, que aqueles contingentes são lançados ao desemprego, às migrações forçadas, à subhabitação, à sub-escolarização e a outras tanta "fomes".

Bem se pode notar como essas linhas de força dos processos sociais presentes impactam a realidade do Ribeira. Atravessadas por dinâmicas que colocam em questão a homogeneidade da noção de agricultura familiar( Schneider: 2003 ), por exemplo, as 
posses do Ribeira parecem manifestar uma inviabilidade no que toca a critérios de produtividade (Garcia Jr. \& Grynszpan: 2002 ). Tendo em conta as tensões e desafios que tal situação comporta, os arranjos familiares que ali se apresentam, em particular relacionados ao direito à terra, carregam uma conflitualidade, e se abrem para saídas claramente individualizadas, para variados trânsitos, locais e extra-locais, acionados em particular pelas gerações mais novas, complexificando a oposição rural/urbano, apontando para a redefinição de modelos do rural, e para a análise das redes sociais e representações a elas ligadas.

Por outro lado, não se pode desconsiderar os modos pelos quais os agentes sociais, em particular os sitiantes, posseiros, arrendatários e assalariados, refletem sobre tais processos, e se apropriam diferencialmente dos recursos materiais e simbólicos que se lhes apresentam. Especialmente, como se reapropriam daqueles recursos que lhes continuam disponíves, entre eles a terra e as formas móveis de incorporá-la. Formas que incluem desde a lógica do parentesco, da herança e do apossamento simples, até as estratégias, habituais ou mais recentes, de reivindicação possessória, bem como de negociação da terra, e de assalariamento complementar, muitas vezes se buscando, através da "reserva" financeira que um patrimônio territorial representa, transitar para a vida urbana.

Um cálculo faz-se presente, envolvendo tanto avaliações referidas a critérios inscritos numa "tradição", já por si aberta à história e às relações com a vida urbana, como a limites e possibilidades postas numa experiência atual, procurando dimensionar tanto recursos de consumo familiar e individual, como aqueles destinados a implementar um projeto de acumulação, ainda que parco, mas indicando uma percepção clara do mundo social de que participam. E não só quanto a recursos econômicos em sentido estrito, mas também quanto a capitais simbólicos: educação, inserção política, etc. Sempre o que se visa contornar é o fechamento efetivo da terra, que parece inevitável, mas ainda, de certa forma, adiável, quando se consegue utilizar estrategicamente os patrimônios, para produzir, para morar, e para negociar.

A mobilidade, nessas circunstâncias, repõe-se como prática fundamental, como fica claro ao se notar que a dinâmica populacional do Vale dirige-se muito pouco para a migração para fora da região. Ela surge, no plano das representações, tal como se 
expressa nas falas dos moradores do Vale, como alternativa a uma plena proletarização, percebida como constitutiva do pólo mais fraco, numa sociedade de capital e trabalho, e negativamente valorada aos olhos de um ethos referido à condição de lavradores autônomos. Ademais, o que se percebe com clareza é a degradação contemporânea de uma condição proletária, em face do encolhimento crescente do mundo do trabalho e das alternativas ocupacionais. Com efeito, esta realidade social nos coloca alguns desafios, e nos sugere redimensionar alguns pressupostos e conclusões elaborados por Antonio Candido.

Assim, vimos Candido ressaltar a importância do provisionamento alimentar como motor de uma estrutura social orientada para a colaboração no trabalho, e que, no caso caipira, manifesta-se no grupo de vizinhança, dentro do qual se tece a solidariedade. Vimos, por outro lado, a partir da realidade empírica do Vale, como é a estrutura de parentesco o fator decisivo para a mobilidade, que assegura, simultaneamente, a incorporação de novas terras ao circuito de relações sociais e a reposição das condições de cultivo. Sabe-se que o parentesco constitui um vínculo simbólico. No Ribeira, ele se apresenta na forma de uma genealogia ( Woortmann: 1995, 92 ) bilateralmente traçada, que define direitos sobre a terra, distribuídos em bairros interligados, entre outras relações, pelas alianças entre as gerações ascendentes, e que assim conformam um espaço de trânsito, repondo as condições da aliança e da herança. Aí se mostra o aspecto prático do simbolismo do parentesco: linguagem que fala de relações sociais, mas na sua dimensão especificamente jurídica. O parentesco fala de direitos, constitui direitos, e se projeta no espaço. Mais do que isto, funda direitos que situam seus detentores nos campos social, jurídico e político, já que dão corpo a uma condição camponesa ( Bourdieu: 1987, 4 ) ${ }^{6}$. O parentesco tem, aí, uma dimensão pública.

6 . A idéia, aqui, é a de Bourdieu, retomando Redfield: a relação com a vida urbana é "característica constitutiva da existência camponesa" . Nesse sentido, uma identidade camponesa, relacional e histórica, refere-se tanto à situação específica de cultivador da terra como à posição relativa do campesinato em uma estrutura objetiva de relações, ambas componentes de uma "condição camponesa". No contexto em foco, esta condição comporta uma auto-representação como possuidores de um direito à terra, porque lhes cabe o papel distintivo de arroteá-la, abri-la ao cultivo, "desbravar" a mata ( MUSSUMECI: 1988 ), incorporando a terra ao mundo social. Tal direito deve ser reconhecido e lhes assegurar um lugar numa ordem geral de relações. Uma vez ameaçado, a identidade desses agentes adquire um cunho político. Essa perspectiva, elaborada a partir das práticas e representações analisadas nas situações de conflito possessório, parece-se suficiente para permitir que se ultrapasse a dicotomia rural/urbano, para interpretar tais processos, em que parece redesenhar-se um ethos por seu aspecto jurídico-político, como habitus cristalizado na definição de um direito, e orientado para a disputa por sua 
Mas qual é o direito de que fala o parentesco, e qual a sua relação com a mobilidade que se sustenta na rede de parentes? É a posse, princípio legal incorporado às práticas sociais, sob distintas formas, e que encontra suas raízes no direito agrário português expresso nas Ordenações, constitutiva de um direito de propriedade, em sentido lato, sob condição de moradia e cultivo. É ela o instrumento de ocupação territorial, de abertura da terra, e de política agrária, na base do regime sesmarial. Transplantado este para a colônia, o princípio da posse não serve apenas ao latifúndio, sustenta a ocupação e o avanço sobre terras livres. Abolido o direito sesmarial com a independência, é a livre posse que, até a Lei de Terras de 1850, orienta o movimento tanto dos grandes proprietários em busca de novas terras como dos pequenos que lhes abrem o caminho, como nota Candido.

Após 1850, a posse tende a restringir-se, do ponto de vista legal. Com a Constituição de 1891, seu objeto primeiro, a terra devoluta, é transferida aos estados, e finalmente, torna-se imprescritível com o Decreto $\mathrm{n}^{\mathrm{o}} 19924$, de 1931, ou seja, inapropriável pela usucapião. Isto quer dizer que legalmente se veta a prática histórica de constituição de um direito de "dono" pela abertura da terra, e pela sua habitação e cultivo. No Ribeira, como em outros lugares, é significativo que, a partir desse momento comecem a se desencadear conflitos em que se embatem supostos proprietários titulares de áreas que nunca ocuparam, e posseiros, que incorporaram tais áreas por meio de suas redes familiares. É a re-significação dessa prática, que compartilha com o mundo social envolvente o valor e direito condensados na posse, que se procura atualizar recorrentemente, em particular na falta de outras alternativas.

Portanto, reforça-se, por este ângulo, mais do que pelo enfoque situado das relações vicinais, voltadas à organização produtiva, a importância do simbolismo do parentesco na geração dos meios de vida, que Candido realça, mas atendo-se a seu aspecto funcional, adaptativo. Tenha-se em vista, de antemão, que um grupo de vizinhos é um grupo de parentes. Ao se incluir o parentesco na análise, a partir de um contexto empírico que manifesta sua centralidade e sua atualidade, é possível entender mais profundamente o sentido decisivo da organização social, enquanto ordenação concebida e praticada, na produção das condições da vida humana.

legitimação ( BOURDIEU, Pierre. 1989."A Força do Direito" in O Poder Simbólico. Lisboa/Rio de Janeiro. DIFEL/Bertrand Brasil, pp. 209-258. 
Assim, é possível indagar se a organização orientada para a mobilidade, que se busca atualizar contemporaneamente em situações diversas, seja nos trânsitos operados no Vale, seja em contextos de acampamentos e assentamentos que, cabe lembrar aqui, marcam-se pelo fenômeno que alguns pesquisadores vêm acompanhando, ou seja, por um perfil populacional composto acentuadamente pela presença de contingentes oriundos do próprio mundo rural paulista ( Miranda: 2003 ), mais do que carregar a ambigüidade de ser, ao mesmo tempo, uma forma de adaptação regressiva, tendendo ao isolamento, e de manifestar uma vitalidade cultural de um mundo rústico cujas condições sociais se esgotam, não é antes re-significada diante de um contexto geral também em movimento. Então, não se trata de pensá-la como uma "latência", inadequada diante das condições presentes, mas como uma reconstrução a partir de um estoque simbólico compartilhado, eficaz em face das condições objetivas que se apresentam a estes agentes sociais, eles próprios transformados na experiência de uma mudança contínua.

Cabe ainda pensar se esta reorganização voltada para a mobilidade - cujo sentido hoje incorpora novas determinações, como vimos - pode ter seus "mínimos" pensados como limites abaixo dos quais uma sociabilidade se desintegra, e recai na anomia. Os exemplos acima, entre outros, são de tentativas de reconstrução de vidas sociais. Como Candido parece adiantar, ao analisar situações de aceitação e de rejeição parciais de novos elementos, reconstruções seletivas incorporando mudanças, respondendo ativamente a elas, constituem respostas eficazes à dinâmica de incorporação aos macro-processos do mundo contemporâneo. Neste, o que parece claro é que aquilo que Candido definiu como o "proposto", passível de ser rejeitado num processo de adaptação, ou seja, a incorporação de uma racionalidade econômica orientada pelo mercado e a individualização das referências, torna-se imposição prática que atinge não só os mundos rurais. $O$ que se pode observar são as diferentes apropriações que se fazem desses valores, definindo-se, então, novas e distintas identidades, condições e trajetórias.

Em suma, o que se pode defender é a idéia de que a plasticidade desse "modelo" móvel de sociabilidade, fundada, em boa parte, embora hoje não exclusivamente, nas relações de parentesco, tanto internas à família conjugal como relativas a um círculo maior de "parentes", vem sendo estratégica para estas populações rurais que incorporam 
localmente transformações econômicas, políticas, culturais, técnicas. Estar atento para fenômenos empíricos que possam manifestar a eficácia da mobilidade, como resposta a uma diversidade de situações que um processo geral de deslocamento produz, é o objetivo das considerações aqui desenvolvidas.

Esta eficácia da mobilidade, e do parentesco que a sustenta, manifesta-se freqüentemente, como mostra um conjunto de pesquisas, na trajetória de migração para as cidades. São as redes de parentes já migrados que orientam as saídas, indicam possibilidades de trabalho, acolhem o recém-migrado. Em contrapartida, no local de origem em geral se mantém aberta a possibilidade do retorno, tanto daqueles cuja migração é temporária ou cíclica, quanto dos que a princípio a tomaram como saída definitiva. E este retorno é assegurado pela inserção da pessoa no grupo familiar, restrito ou ampliado, em particular nos casos em que fica mantido o direito de herança sobre o patrimônio territorial.

São justamente os laços de sociabilidade que se refazem na metrópole, oferecendo uma referência coletiva a quem migra ( Oliven: 1985 ). Nos casos brasileiros, vimos que estes laços são privilegiadamente os de parentesco ( Rigamonte: 2001). E parece que são eles que propiciam a moldura dentro da qual são relidos os valores religiosos, constróem-se dimensões da identidade que incorporam a individualização e a orientação que privilegia o interesse econômico.

A região do Ribeira, como visto, é relevante para se observar tais processos. Paradoxalmente a região "mais atrasada" do estado mais desenvolvido, nela incidem dinâmicas gerais, ligadas à questão agrária, ao preservacionismo, ao processo de urbanização, que ali é mediado pelas pequenas e médias cidades tendentes, no momento, a concentrar a população que deixa o campo, bem como à política de captação de recursos hídricos. Ali, especialmente, aciona-se a estratégia da mobilidade, na tentativa de repor os sítios, agora não só como terra de moradia e cultivo, mas como reserva de valor, possibilidade de produção para o auto-consumo, em face da ausência de alternativas de trabalho, e local de habitação.

Deve ser lembrado que, como nota Candido, o sítio constitui a condição percebida como mais vantajosa, regular e estável para fazer face à mudança, em particular porque abriga o camponês "fixado" na herança e envolvido na trama de relações que constitui o bairro. O que ele não ressalta é a importância do pólo 
complementar, o da família que se move para além do território do bairro, conjunto de sítios, constituindo novas oportunidades de fixação, de herança, e de movimento permanente no sentido de repor, senão a terra, as condições de vida. Em outras palavras, nesses universos, a terra, e, por comparação, outros recursos, só se incorporam e se fixam, temporariamente, pela disponibilidade ao movimento. É, portanto, a imagem do sítio, que assegura a condição de produtor autônomo porque "dono" da terra, a referência que orienta a mobilidade. Re-significada no presente, torna-se um capital, simbólico e material, almejado na medida em que facilita os trânsitos necessários à reposição das condições de vida.

Pensar a temática da ruralidade desde um tal contexto, que carrega especificidades, mas também compartilha determinantes mais gerais com o mundo rural e com a sociedade brasileira em seu conjunto, implica em situar tal temática neste universo de significações e de práticas que se orienta, dentro de seus possíveis, para atualizar constantemente um espaço social de existência. Espaço este que supõe o reconhecimento da legitimidade de suas demandas, projetos e expectativas. Esta busca constante, em face das possibilidades e limites postos pela sociedade englobante, guarda aspectos compartilhados das experiências de deslocamento que incidem com particular força sobre as classes subalternas, informando estratégias para contornar tais limites.

\section{BIBLIOGRAFIA}

AUGÉ, Marc. 1994. Não-Lugares: Introdução a uma Antropologia da Supermodernidade. Campinas. Papirus, col. Travessia do Século.

BOURDIEU, Pierre. 1987. "Campo do Poder e Habitus de Classe" in $A$ Economia das Trocas Simbólicas. São Paulo. Perspectiva.

. 1989. "A identidade e a representação. Elementos para uma reflexão crítica sobre a idéia de região" e "A Força do Direito" in $O$ Poder Simbólico. Lisboa/Rio de Janeiro. DIFEL/Bertrand Brasil, pp.107-132 e 209-258. 
CANDIDO, Antonio. 1979. Os Parceiros do Rio Bonito. São Paulo. Livraria Duas Cidades, $5^{\text {a }}$ edição.

GARCIA Jr., Afrânio \& GRYNZPAN, Mário. 2002. "Veredas da Questão Agrária e Enigmas do Grande Sertão" in MICELI, Sérgio ( org. ). O que ler na ciência social brasileira 1970-2002. São Paulo/Brasília. Ed. Sumaré/ANPOCS/CAPES, vol. IV, pp. 311-348.

GIDDENS, Anthony. 1991. As Conseqüencias da Modernidade. São Paulo. Ed.Unesp.

JACKSON, Luiz Carlos. 2002. A Tradição Esquecida: Os Parceiros do Rio Bonito e a Sociologia de Antonio Candido.Belo Horizonte/São Paulo. Ed. UFMG/FAPESP.

MIRANDA, Maria Elena. 2003. Os Assentados frente aos Desafios Legais uma interpretação antropológica das relações jurídicas no assentamento de Promissão. São Paulo. FFLCH/USP. Tese de doutoramento apresentada ao Programa de Pósgraduação em Antropologia Social.

MULLER, Geraldo. 1980. “Estado, Estrutura Agrária e População: Ensaio sobre Estagnação e Incorporação Regional”. Cadernos CEBRAP. Petrópolis, Vozes/CEBRAP, $\mathrm{n}^{\mathrm{o}} 32$.

MUSSUMECI, Leonarda. 1988. O Mito da Terra Liberta: colonização espontânea, campesinato e patronagem na Amazônia Oriental. São Paulo. ANPOCS/Vértice.

OLIVEN, Ruben. 1985. A Antropologia dos Grupos Urbanos. Petrópolis. Vozes.

PALACIOS, Guillermo. 1993. "Campesinato e Historiografia no Brasil: Comentários sobre algumas Obras Notáveis". $B I B \mathrm{n}^{\mathrm{o}} 75$, Rio de Janeiro. RelumeDumará/ANPOCS, $1^{\circ}$ semestre, pp. 41-57.

PAOLIELLO, Renata Medeiros. 1992. Conflitos Fundiários na Baixada do Ribeira; a posse como direito e estratégia de apropriação. Campinas. IFCH/UNICAMP/PPGAS, dissertação de mestrado. . 1998. "Estratégias Possessórias e Constituição de Espaços Sociais no Mundo Rural Brasileiro: o contexto da Baixada do Ribeira" in NIEMAYER, Ana Maria \& PIETRAFESA DE GODOI, Emília ( orgs. ). Além dos 
Territórios; para um diálogo entre a etnologia indígena, os estudos rurais e os estudos urbanos. Campinas. Ed. Mercado de Letras, pp.201-227. - 1999. As Tramas da Herança: da reprodução camponesa às atualizações dos sentidos da transmissão da terra. São Paulo. FFLCH/USP/PPGAS, tese de doutoramento.

PASSIANI, Enio. 2002. “Como nascem os Clássicos”.Revista Brasileira deCiências Sociais. São Paulo/Bauru. ANPOCS/EDUSC/FAPESP, vol. 17, $\mathrm{n}^{\mathrm{0}}$ 50, outubro, pp. 174-176.

PETRONE, Pasquale. 1966. "A Baixada do ribeira: Estudos de Geografia Humana”. Boletim de Geografia. São Paulo. FFLCH/USP, nº 283.

QUEIROZ, Maria Isaura Pereira de. 1967. Vale do Ribeira: Pesquisas Sociológicas. São Paulo. DAEE/USP, relatório de pesquisa. . 1973. Bairros Rurais Paulistas: dinâmica das relações bairro rural-cidade. São Paulo. Livraria Duas Cidades.

RIGAMONTE, Rosani. 2001. Sertanejos Contemporâneos: entre a metrópole e o sertão. São Paulo. Humanitas/FAPESP.

SANTOS, Luiz Antonio Castro. 2002. "A Radicalidade de Os Parceiros do Rio Bonito". Revista Brasileira de Ciências Sociais. São Paulo/Bauru. ANPOCS/EDUSC/FAPESP, vol.17, nº 49, junhp, pp. 31-38.

SCHNEIDER, Sérgio. 2003. A Pluriatividade na Agricultura Familiar. Porto Alegre. UFRGS/BNDE/PGDR.

VINCENT, Joan. 1987. “A Sociedade Agrária como Fluxo Organizado; Processos de Desenvolvimento Passados e Presentes" in BIANCO, Bela Feldman ( org. ). Antropologia das Sociedades Contemporâneas. São Paulo. Global/Universitária, pp. $345 / 402$.

WANDERLEY, Maria de Nazareth Braudel. 1996. Raizes Históricas do Campesinato Brasileiro. Caxambu. XX Encontro Anual da ANPOCS. Comunicação ao GT Processos Sociais Rurais.

WOORTMAN, Ellen. 1995. Herdeiros, Parentes e Compadres. São Paulo/Brasília. Hucitec/EdUnB. 